\title{
Impact of high-speed rail on intercity travel behavior change: The evidence from the Chengdu-Chongqing Passenger Dedicated Line
}

\section{Xiaohong Ren}

Chongqing Jiaotong University

allison721@outlook.com

\section{Fang Wang}

Chongqing Jiaotong University

Chunyang Wang (corresponding author)

Chongqing University

30376022@qq.com

\author{
Zhenhua Chen \\ The Ohio State University
}

Jiamei Wang

Chongqing Jiaotong University

Ting Dan

Chongqing Jiaotong University

\section{Zongyang Du}

Nankai University

\begin{abstract}
This paper investigates the impact of high-speed rail (HSR) on intercity travel behavior changes using the Chengdu-Chongqing (Chengyu) Passenger Dedicated Line (PDL) as an example. Based on the statistical analysis of survey data that consists of 1384 samples, the result shows that HSR has become the primary mode of intercity travel between Chengdu and Chongqing. Specifically, travel demand has increased by $60 \%$ after the operation of the HSR system and the demand change is affected by several factors, such as trip purpose, gender, and travel time savings. The result also shows that the variation of travel demand in both directions declined after the opening of HSR, which suggests that HSR tends to promote a convergent growth of intercity travel demand. Although most passengers ride the Chengyu HSR for a personal reason, the number of riders using it for commuting and business purposes has also increased substantially. Overall, the study confirms that the economic link between Chengdu and Chongqing has been enhanced by the operation of HSR.
\end{abstract}

Keywords: High-speed rail, intercity travel demand, trip intensity, Chongqing, Chengdu

\section{$1 \quad$ Introduction}

Travel behavior has a close linkage with transportation infrastructure. Transportation infrastructure facilitates passengers and freight flows given reduced transportation costs and increased accessibility. For instance, Ma, Wang, and Liu (2012) found that a $1 \%$ reduction in travel time is associated with a $0.8 \%$ travel demand increase in China based on a comprehensive travel survey analysis. High-speed rail

Copyright 2019 Xiaohong Ren, Zhenhua Chen, Fang Wang, Jiamei Wang, Chunyang Wang,Ting Dan, \& Zongyang Du http://dx.doi.org/10.5198/jtlu.2019.1302

ISSN: 1938-7849 | Licensed under the Creative Commons Attribution - Noncommercial License 4.0

The Journal of Transport and Land Use is the official journal of the World Society for Transport and Land Use (WSTLUR) and is published and sponsored by the University of Minnesota Center for Transportation Studies.

\section{Article history:}

Received: September 1, 2017

Received in revised form:

June 6, 2018

Accepted: January 27, 2019

Available online: April 15, 2019 
(HSR), ${ }^{1}$ as one of the advanced passenger transportation systems, has fundamentally changed the intercity travel experience due to its effect on compressing time and space (Perl \& Goetz, 2015; Zhou, 2015).

HSR development was initiated in 2004 in China, with the objective to serve over $80 \%$ of the population by 2025. With strong governmental support, the HSR system developed so rapidly that the initial plan of a network consisting of four-horizontal and four-vertical HSR trunk lines was completed nearly three years ahead of the schedule. To date, the system includes a total HSR length of over 25 thousand kilometers, which accounts for over $66 \%$ of HSR tracks worldwide. While people enjoy the convenience brought by HSR, several key issues pertaining to the effectiveness of HSR on intercity travel demand remain unclear. For instance, how does HSR affect travel demand changes? And what are the implications of travel behavioral changes caused by HSR on future transportation planning and development?

To address these questions, our study utilizes the Chengdu-Chongqing (Chengyu) Passenger Dedicated Line (PDL) as an example. We believe that the Chengyu PDL provides a unique case to examine the impact of HSR on travel behavioral changes in the less developed regions of China. In addition, the investigation of HSR's influence on intercity travel behavioral changes also helps us to clarify whether the development of HSR has any effect on promoting regional economic integration between two major cities (Chengdu and Chongqing).

Another highlight of this research is that unlike previous studies that investigated the issue from a static perspective, our study evaluates the impacts of HSR on travel demand with a focus on examining the shifting behavior change after the operation of HSR. ${ }^{2}$ Furthermore, the spatial variations of travel demand are also evaluated through a comparison of trip intensity indices of different origin-destination (OD) pairs. We believe that such a comparison is critical to ensuring the dynamic variation of intercity travel demand caused by HSR is captured adequately. In addition, a valid understanding of travel demand through a spatiotemporal analysis could also improve the accuracy of travel forecast and economic impact analyses (Chen, Xue, Rose, \& Haynes, 2016), which may eventually improve the efficiency of HSR operation and the effectiveness of future infrastructure investments.

The rest of the paper is organized as follows. Section 2 reviews the relevant literature. Section 3 introduces the data. Section 4 discusses the characteristics of Chengyu intercity travel demand. Section 5 presents empirical results, and section 6 summarizes and concludes.

\section{$2 \quad$ Literature review}

Although the impact of HSR has been evaluated extensively in the literature, the understanding of the impact of HSR on intercity travel behavior changes remains limited. To identify the research gap specifically, the following review focuses on four aspects: accessibility, economic effect, urban spatial restructuring, and intercity travel behavior.

The impact of HSR on urban accessibility has been evaluated extensively using various methods, such as network topology, the grid method, the spatial syntax method, and GIS. It is generally believed that the space-time compression brought by HSR has a significant effect on improving regional accessibility (Gutiérrez, Gonzalez, \& Gomez, 1996; Jiang et al., 2016; Jiao, Wang, Jin, \& Dunford, 2014;

\footnotetext{
${ }^{1}$ There are two types of premium passenger train services in China: D-train and G-train. The former is usually operated on a conventional rail line with an operating speed of $160-250 \mathrm{~km} / \mathrm{h}$. Instead, G-train is more advanced than the D-train as it usually operated on dedicated passenger rail lines at a speed of 250-350 km/h. In this paper, HSR refers to G-train only.

${ }^{2}$ A shifting behavior change refers to the fact that our analysis focuses on the understanding of to what extent the travel demand is shifted to HSR after the operation of the system. Hence, our analysis does not capture the demand change of transportation modes, such as automobile or transit.
} 
Chen, 2012). However, other studies also revealed that although accessibility has significantly improved over the past decade in China (Shaw, Fang, Lu, \& Tao, 2014), the effects were found to vary substantially due to different regional characteristics (Zhong, Huang, \& Wen, 2015). In particular, some studies revealed that HSR tends to enhance the intercity connection of only hub cities (Jin \& Wang, 2004; Wang \& Jin, 2005). Hence, urban agglomeration and labor force evolution may be facilitated as a result of HSR development (Kim, 2000; Garmendia, Ribalaygua, \& Ureña, 2012; Chen \& Hall, 2011; Haynes, 1997). With HSR the simulation suggests that land development is accelerated (Yu, Chen, Martínez, \& de Abreu e Silva, 2015).

In terms of the economic effects of HSR, the research findings in the literature appear to be mixed. For instance, some studies found that travel time savings brought by HSR could generate a positive economic benefit through productivity improvement (Rietveld, 1989; Chen, Z., et al., 2016). However, other studies suggested that the economic effects of transportation systems can be negligible or, in some cases, even negative due to spillover effects (or redistributional effect) (Boarnet, 1996). Some studies suggested that HSR can have a negative effect on peripheral cities while benefiting major central cities (Hall, 2009). For instance, Chen and Haynes (2015a) found that the opening of HSR between Beijing and Shanghai has a significant impact on housing price increases in small and medium-sized cities, but the impact is found to be negligible in provincial capital cities. It should be noted that most of these studies examined the economic effect of HSR at an aggregate level, whereas assessments at a disaggregated or individual level are still scant (Long, Meng, \& Li, 2019).

The impact of HSR has also been examined from the perspective of urban spatial restructuring, but it is still unclear whether the introduction of HSR leads to a polarization or convergence of urban spatial structures. For instance, Kivisto (2012) indicated that urban transformation and regional spatial structuring are affected by modern technologies, such as HSR, aviation, and Internet. In addition, scholars also argued that HSR may lead to positive outcomes of urban spatial restructuring, such as improvements of regional conditions (Gutiérrez, 2001), promotion of industrial structure (Chen \& Hall, 2012), economic growth (Campos \& de Rus, 2009), and the fostering of regional competition and cooperation (Ding, Jin, Wang, \& Liu, 2013). Hence, spatial structure can be transformed from an unbalanced, single-centered form to a balanced, multi-centric form (Fang \& Sun, 2014). Conversely, regional agglomeration may also be facilitated by HSR, as observed by other scholars. For instance, $\mathrm{Li}$, Jiang, and Lou (2009) found that HSR is likely to enhance the role of regional hub cities after it goes into operation. Li, Liu, and Cao (2014) further confirmed that HSR has a strong agglomeration effect on economic activities, due to their finding that the degree of homogeneity increases among cities in terms of population, industry, and economic development patterns. A similar pattern was also confirmed in the European HSR system (Cheng, Loo, \& Vickerman, 2015).

Although the impact of HSR on travel behavioral changes has received increasing attention, there is still a lack of clear understanding of this issue. Some studies, such as Chan and Yuan (2017), found that people opted to ride HSR more often for tourism-related purposes after the opening of the ShenzhenXiamen HSR. Chen, Sun, Zhu, and Zeng (2016) found that HSR was more frequently used for commute after the opening of the Beijing-Shanghai HSR. Other studies indicated that HSR has changed both the spatial perception of travelers and the spatial distribution of travel demand (Hou, Liu, Zhang, \& Hu, 2011; Li et al., 2014; Long \& Meng, 2015; Li, Zhu Li, Ma, \& Gu, 2006; Mou, Li, \& Cui, 2014).

Although the aforementioned studies attempted to reveal the travel behavioral changes caused by the operation of HSR in China, most of the studies were conducted at an aggregated level without a comparison of the change in travel demand from a shifting behavior perspective. There is also a lack of focus on the different effects of demand change. As revealed by Givoni and Dobruszkes (2013), HSR tends to have a strong substitution effect on other transportation modes due to its advantage of speed. 
In addition, demand may also be induced if the capacity of transportation infrastructure is expanded (Cascetta, Papola, Pagliara, \& Marzano, 2011). It is clear that HSR is likely to affect travel behavioral changes, both through a substitution effect and an induced demand effect (Chen, Z., et al., 2016), but unfortunately there is still a lack of empirical evidence to reveal how the travel demand of HSR is affected by these different effects (Givoni \& Dobruszkes, 2013).

In sum, our study is intended to fill research gaps in the following aspects: First, our study provides a detailed empirical assessment of HSR's impact on travel demand change, with a focus on shifting behavior changes through a before-after comparison. Second, unlike previous studies that focused on HSR in developed regions, our assessment focuses on the Chengyu corridor, which is located in a less developed region of China. We believe that such a focus will provide meaningful implications to advance future policy-makings related to infrastructure investments and economic development in less developed regions. Third, our study reveals the spatiotemporal variations of HSR's impacts on intercity travel demand change based on a detailed assessment of the survey results.

\section{Study area and data sources}

\subsection{Study area}

The Chengyu corridor connects two major metropolitan cities in the southwest of China - Chengdu and Chongqing - with a distance of $500 \mathrm{~km}$. Chengdu (with the abbreviation "Cheng"), is the capital city of the Sichuan province, whereas Chongqing (with the abbreviation "Yu"), is one of the key municipalities in China. As illustrated in Table 1, although Chongqing is much larger than Chengdu in terms of geographic area and population, its economic vitality is less vigorous than Chengdu in terms of GDP and income per capita.

Table 1. The comparison of socioeconomic characteristics between Chengdu and Chongqing

\begin{tabular}{lll}
\hline Feature & Chengdu & Chongqing \\
\hline Per capita disposable income of urban residents (yuan) & 35,902 & 29,610 \\
Per capita disposable income of rural residents (yuan) & 18,605 & 11,549 \\
Per capita GDP (yuan) & 76,960 & 57,902 \\
Primary industry added value (100 million yuan) & 475 & 1,303 \\
Secondary industry added value (100 million yuan) & 5,202 & 7,756 \\
Tertiary industry added value (100 million yuan) & 6,493 & 8,500 \\
Primary industry added value accounted for GDP (\%) & 3.90 & 7.35 \\
Secondary industry added value accounted for GDP (\%) & 42.99 & 44.52 \\
Tertiary industry added value accounted for GDP (\%) & 53.11 & 48.13 \\
Resident population (millions of people) & 15.92 & 30.48 \\
Administrative area (millions of km2) & 143,35 & 824,02 \\
\hline
\end{tabular}

Data Source: China Statistical Yearbook, Chongqing Statistical Yearbook, Chengdu Statistical Yearbook; Statistics Bulletin of National Economic and Social Development of Chengdu and Chongqing.

The transportation linkages between Chengdu and Chongqing have experienced different stages of development since the establishment of the nation. The first railway in this corridor was built in 1952; it was used for both freight and passenger transport, and the average travel time between Chengdu and Chongqing was about 12 hours. More than fifty years later, the second conventional railway (known 
as "Cheng-Sui-Yu") was developed in 2006. Given that this is a ballastless rail system, the travel time between the two cities reduced substantially to 5 hours. However, the true HSR in this corridor was not established until 2015. The new HSR system has a distance of $307 \mathrm{~km}$ and consists of 10 intermediate stations (see Figure 1). The system is designed with a maximum speed of $350 \mathrm{~km} / \mathrm{h}$. As a result, the average travel time between Chengdu and Chongqing has further reduced to only 1.5 hours.

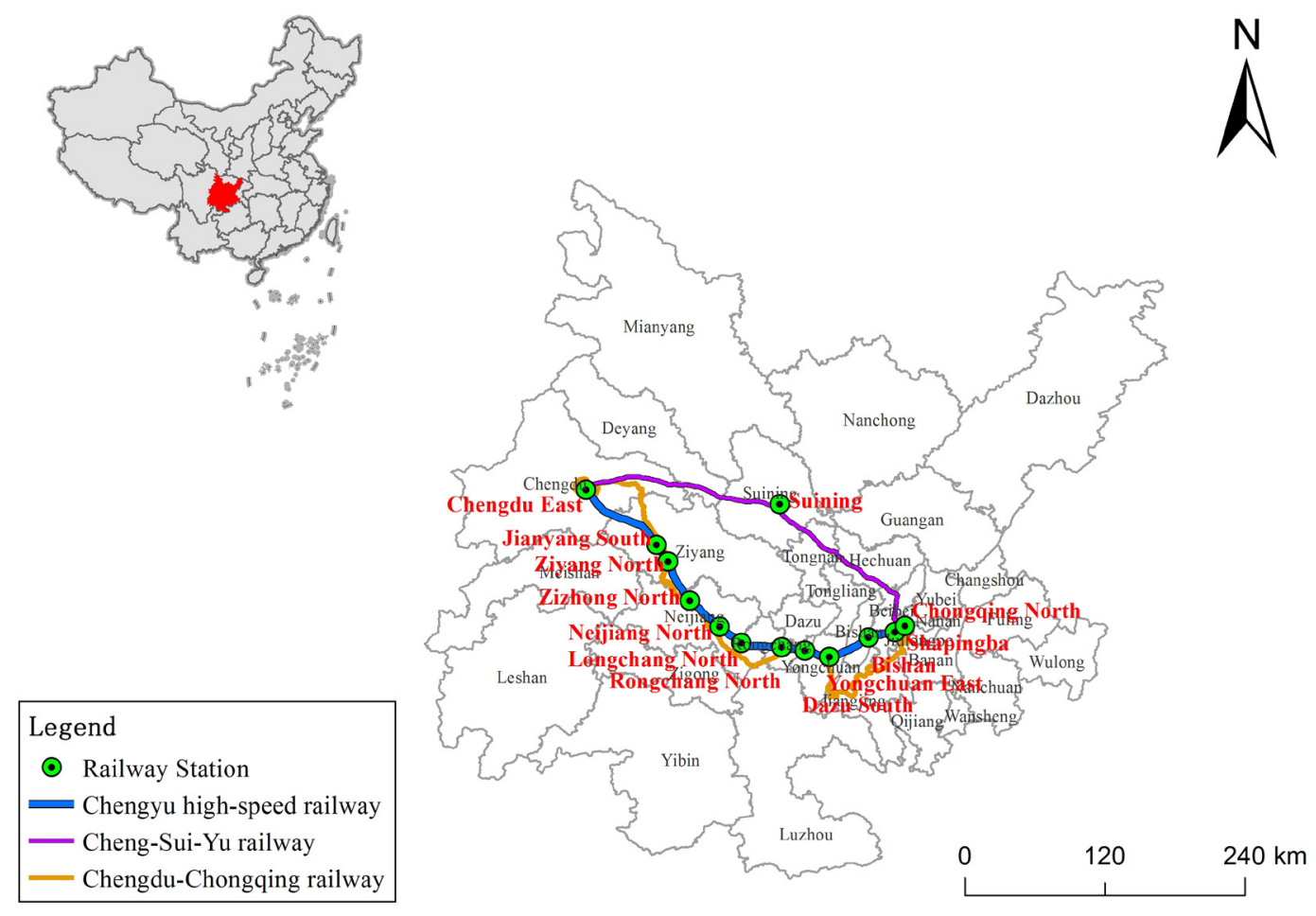

Note: Railway stations are marked in red.

Figure 1. The map of the study area: Chengdu-Chongqing corridor

Because aviation service between Chengdu and Chongqing was cancelled after the D-train went into operation in 2009, highway and rail are the major modes of transportation in this corridor. As illustrated in Table 2, in addition to four different rail services, intercity bus service is also a major mode of intercity travel. 
Table 2. The comparison of travel choice between Chengdu and Chongqing

\begin{tabular}{|c|c|c|c|c|c|c|}
\hline No. & Modal Choice & $\begin{array}{l}\text { Length } \\
(\mathrm{km})\end{array}$ & $\begin{array}{l}\text { Top speed } \\
(\mathrm{km} / \mathrm{h})\end{array}$ & $\begin{array}{l}\text { Travel } \\
\text { time }\end{array}$ & $\begin{array}{l}\text { Opening } \\
\text { month and year }\end{array}$ & $\begin{array}{l}\text { Fare } \\
\text { cost (¥) }\end{array}$ \\
\hline 1 & Cheng-Yu Conventional Rail & 504 & 60 & $12 \mathrm{~h} 10 \mathrm{~m}$ & Jul 1952 & 42.0 \\
\hline 2 & $\begin{array}{l}\text { Cheng-Sui-Yu Rail (conventional } \\
\text { train) }\end{array}$ & 274 & 200 & $5 \mathrm{~h}$ & Jul 2009 & 46.5 \\
\hline 3 & Cheng-Sui-Yu Rail (D-train) & 274 & 200 & $2 \mathrm{~h} 13 \mathrm{~m}$ & Jul 2009 & 96.0 \\
\hline 4 & Cheng-Yu HSR (G-train) & 308 & 350 & $1 \mathrm{~h} 43$ & Dec 2015 & 154.0 \\
\hline 5 & $\begin{array}{l}\text { Cheng-Yu Highway (private } \\
\text { automobile) }\end{array}$ & 338 & 80 & $3-4 h$ & Sep 1995 & $324.0^{\mathrm{a}}$ \\
\hline 6 & $\begin{array}{l}\text { Cheng-Sui-Yu Highway (private } \\
\text { automobile) }\end{array}$ & 295 & 120 & $3 \mathrm{~h}$ & Oct 2007 & $286.5^{\mathrm{a}}$ \\
\hline 7 & $\begin{array}{l}\text { Yu-Rong Highway (private } \\
\text { automobile) }\end{array}$ & 254 & 120 & $2 \mathrm{~h} 30 \mathrm{~m}$ & Sep 2017 & $291.0^{\mathrm{a}}$ \\
\hline 8 & Cheng-Yu Highway (bus) & 360 & 120 & $3-4 h$ & Sep 1995 & $77-110^{a}$ \\
\hline
\end{tabular}

Notes: a. The fare represents the cost of using private vehicle, which includes tolls and fuel. The toll of the Cheng-Yu Highway (G76), the Cheng-Sui-Yu Highway (G93) and the Yu-Rong Highway (G5013) are ¥155, ¥139 and ¥164, respectively. The fuel cost is calculated by assuming the rate is at $¥ 0.5$ per $\mathrm{km}$.

Source: Authors' collection.

\subsection{Data}

The data utilized in this analysis was obtained from various sources. For instance, socioeconomic data was obtained from statistical yearbooks, whereas travel behavior data was collected from a travel survey. Specifically, a questionnaire-based survey and face-to-face interviews were conducted simultaneously at the two terminal stations - the Chengdu East Railway Station and the Chongqing North Railway Station-between May 21-27, 2017, from 7 am to $10 \mathrm{pm}^{3}{ }^{3}$ The survey captured passenger flow in both directions between Chengdu and Chongqing. A total number of 1,870 questionnaires were distributed, and 1,810 responses were received. In the end, 1,384 responses were identified as effective, 616 of which were collected at the Chongqing North Station; the remaining responses were collected at the Chengdu East Station. The descriptive statistics of the survey respondents are summarized in Table 3.

\footnotetext{
${ }^{3}$ The survey questionnaire is included in Appendix 1.
} 
Table 3. Descriptive statistics of the survey respondents

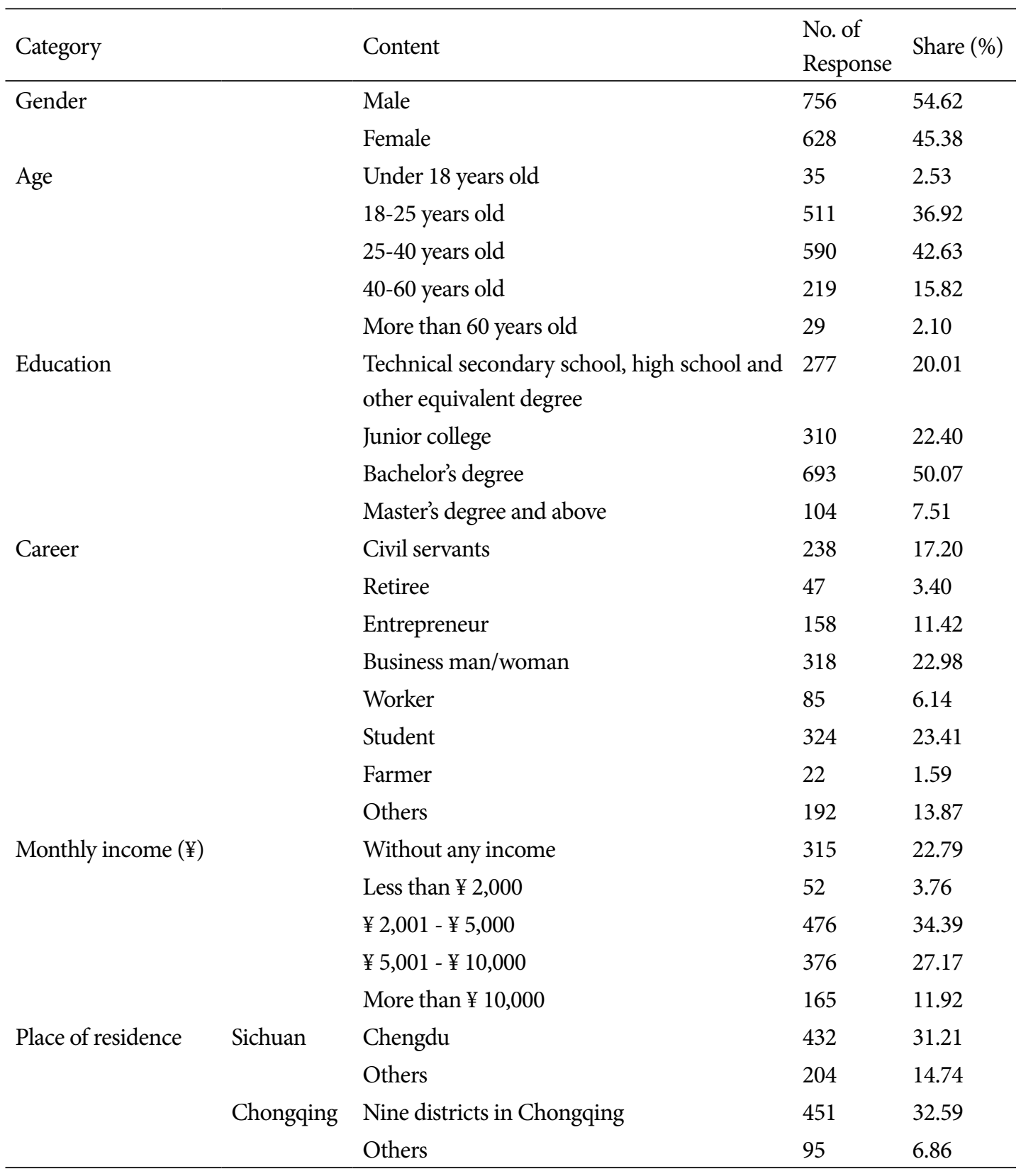

Source: Authors' collection.

The age of respondents ranges from under 18 to 60 . In addition, the majority of respondents were male, with higher education and income levels. Specifically, the share of male respondents was $4.3 \%$ higher than that of the cities' average. In terms of educational background, $80 \%$ of respondents had a higher education degree. 


\section{$4 \quad$ Characteristics of the intercity travel behavior}

\subsection{Mode choice}

The variation of mode choice before and after the operation of the Chengyu HSR was examined. As illustrated in Table 4, 40.9\% and 40.7\% of respondents indicated that intercity bus and conventional passenger rail were adopted, respectively, before the opening of HSR. However, the rates reduced substantially after its opening. Overall, $98.1 \%$ of the respondents indicated that HSR became their primary mode for intercity travel after the opening of the Chengyu HSR.

This change of mode choice was also found to vary across different income groups, although the variation is relatively small. For instance, on one hand, the level of substitution from other modes, such as conventional train, bus and taxi, tends to be considerable in high-income group (with a monthly income over $¥ 10,000)$. On the other hand, the level of substitution from private vehicles is less substantial in high-income group as opposed to groups with lower incomes. Such a result confirms that the level of income does affect the use of private vehicles. More interestingly, the result also shows that the use of HSR is less sensitive to the level of income. Specifically, the mode choice for HSR ranges from $96.2 \%$ to $99.2 \%$, suggesting that most travelers consider HSR as the primary mode for intercity travel between Chengdu and Chongqing.

Table 4. The comparison of modal choice before and after the operation of the HSR

\begin{tabular}{|c|c|c|c|c|c|c|c|c|c|c|c|c|}
\hline \multirow[b]{2}{*}{ Types } & \multicolumn{2}{|c|}{$\begin{array}{c}\text { Without any } \\
\text { income }\end{array}$} & \multicolumn{2}{|c|}{$\begin{array}{c}\text { Less than } ¥ \\
2,000 \\
\end{array}$} & \multicolumn{2}{|c|}{$¥ 2,001-5,000$} & \multicolumn{2}{|c|}{$¥ 5,001-10,000$} & \multicolumn{2}{|c|}{$\begin{array}{c}\text { More than } \\
¥ 10,000\end{array}$} & \multicolumn{2}{|c|}{ Overall } \\
\hline & Before & After & Before & After & Before & After & Before & After & Before & After & Before & After \\
\hline HSR & - & 97.14 & - & 96.15 & - & 97.90 & - & 99.20 & - & 98.79 & - & 98.12 \\
\hline $\begin{array}{l}\text { Conventional } \\
\text { Train }\end{array}$ & 45.71 & 6.03 & 51.92 & 3.85 & 39.08 & 1.68 & 42.55 & 0.80 & 27.88 & 0.00 & 40.68 & 2.31 \\
\hline $\begin{array}{l}\text { Commercial } \\
\text { Bus }\end{array}$ & 46.35 & 0.32 & 40.38 & 3.85 & 46.22 & 2.52 & 35.64 & 1.60 & 27.27 & 0.00 & 40.90 & 1.52 \\
\hline $\begin{array}{l}\text { Corporate } \\
\text { Shuttle Bus }\end{array}$ & 0.32 & 0.00 & 3.85 & 0.00 & 1.68 & 0.42 & 3.99 & 0.53 & 3.03 & 1.21 & 2.24 & 0.43 \\
\hline $\begin{array}{l}\text { Private } \\
\text { Vehicle }\end{array}$ & 12.38 & 1.90 & 13.46 & 0.00 & 16.81 & 1.89 & 28.99 & 5.59 & 53.94 & 8.48 & 23.41 & 3.61 \\
\hline Taxi & 0.95 & 0.32 & 0.00 & 0.00 & 1.05 & 0.21 & 0.80 & 0.53 & 1.21 & 0.00 & 0.94 & 0.29 \\
\hline
\end{tabular}

Notes: All numbers are measured in percent. Multiple selections were allowed in the survey.

Source: Authors' collection.

In addition, the survey shows that passengers were also concerned about factors such as speed, amenities, and on-time performance, each of which has a response rate of $76.8 \%, 51.9 \%$ and $39.5 \%$, respectively. Surprisingly, the results show that passengers are less concerned about fare and safety, as only $19.8 \%$ and $26.6 \%$ of the respondents indicated that these factors affected their decisions of mode choice. Overall, the result confirms that HSR has become the preferred mode for intercity travel between Chengdu and Chongqing. 


\subsection{Trip purpose}

Trip purposes before and after the operation of HSR are compared in Figure 2. The main trip purposes include returning home, business, visiting relatives and friends, and shopping. Although the share of study-related trips (e.g., going to school for a higher education) experienced a slight decrease after the opening of HSR, the number of other trips, such as returning home, tourism, business, and visiting friends and relatives all increased after the system went into operation. The trip purpose of visiting relatives and friends experienced the highest growth (by 4.0\%) after the opening of HSR. The trip purposes for tour-shopping and business also experienced rapid growth. In sum, the results suggest that business activities are faciliated and the socioeconomic linkages are also enhanced between Chengdu and Chongqing after the opening of HSR.

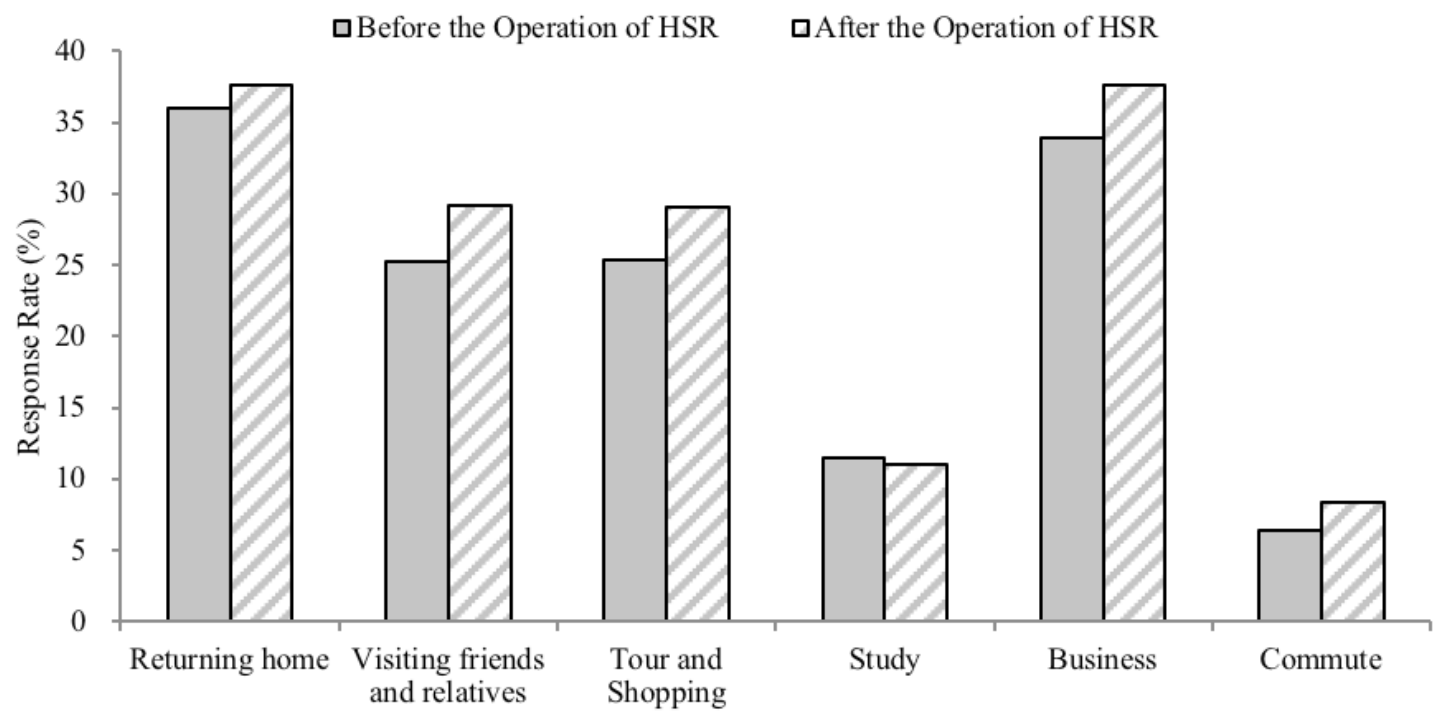

Note: Multiple trip purposes are allowed in the survey.

Source: Authors' collection.

Figure 2. Trip purpose comparison before and after the operation of the Chengyu HSR

\subsection{Spatiotemporal distribution of the travel demand}

Following the research framework developed by Lu (2001) and Hou et al. (2011), the spatiotemporal distribution of intercity travel demand is analyzed in terms of frequency, departure time, trip duration, travel intensity, and direction.

\subsubsection{Frequency}

The change of travel frequency before and after the operation of HSR is illustrated in Figure 3. Again, the results show that people began to travel more frequently after the operation of HSR; the share of respondents who indicated by "never travelled" and "travel once every six months" dropped substantially. Conversely, the proportion of those who traveled at a frequency of either "once a month," "once a week," or "more than once a week" increased significantly after the opening of HSR. 


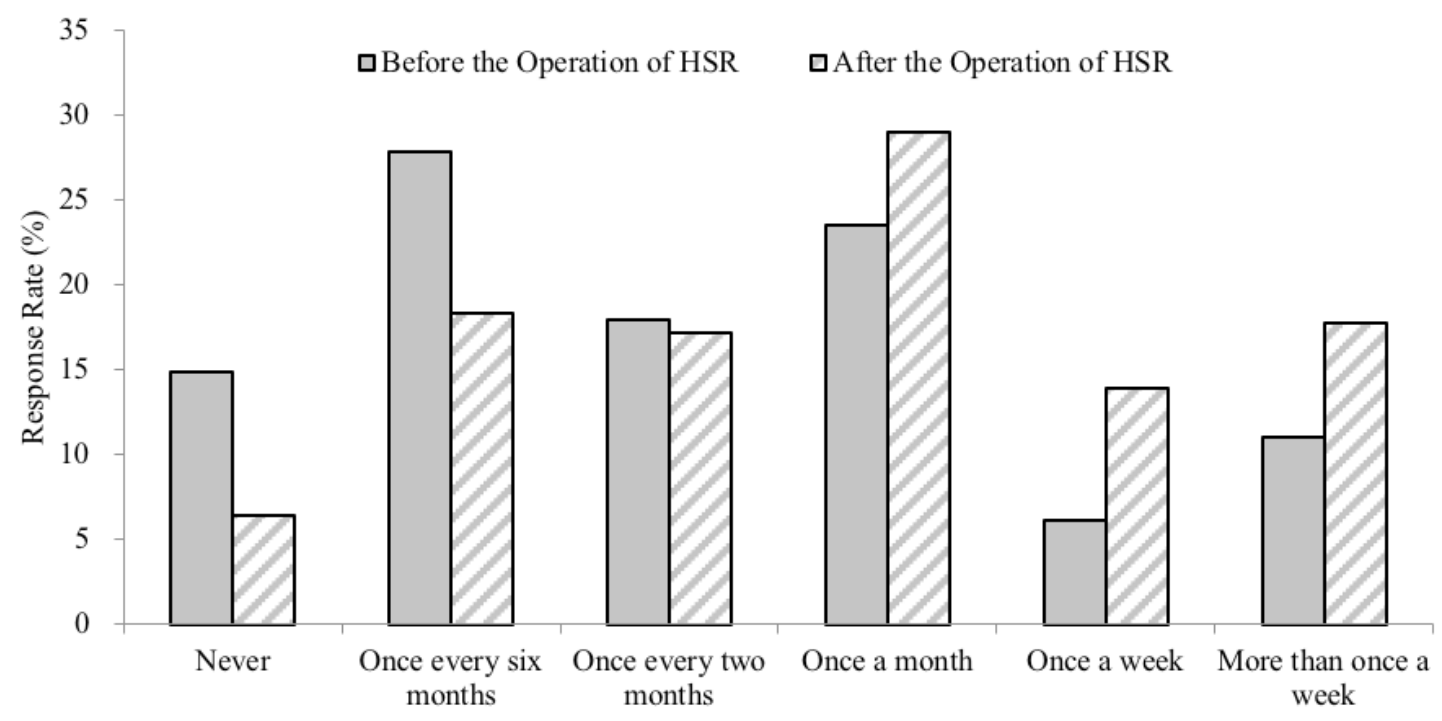

Source: Authors' collection.

Figure 3. Travel frequency comparison before and after the operation of the Chengyu HSR

\subsubsection{Departure time and trip duration}

The changes in departure time and trip duration were adopted to understand whether the flexibility of intercity travel is improved by HSR. As illustrated in Table 5, the ratio of passengers who chose "travel at any time" grew by $8 \%$ after the opening of the HSR. Conversely, the rate of those who chose "travel on the weekend" reduced by $4.9 \%$. In terms of the departure time comparison, the share of passengers who chose to depart in the "early morning" decreased by $12.1 \%$ after the opening of the Chengyu HSR. Instead, the share of all those who selected to depart later in the day experienced an increase. Specifically, the share of those who departed in the "afternoon" expanded by $15.9 \%$. This evidence suggests that HSR has greatly improved the flexibility of the intercity travel between Chengdu and Chongqing.

Trip duration also experienced changes after the opening of the Chengyu HSR. One of the major changes is that passengers who took a round trip within a single day increased by $18.1 \%$ after the opening of HSR. Conversely, the share of passengers with trip duration of "1-3 days" and "4-6 days" decreased by $10.5 \%$ and $4.5 \%$, respectively. This evidence suggests that intercity travel has become much convenient after the opening of HSR. 
Table 5. The change of departure time and trip duration before and after the operation of the Chengyu HSR

\begin{tabular}{|c|c|c|c|c|c|c|}
\hline \multirow[b]{2}{*}{ Field } & \multirow[b]{2}{*}{ Category } & \multicolumn{2}{|c|}{ Before } & \multicolumn{2}{|c|}{ After } & \multirow[b]{2}{*}{$\begin{array}{l}\text { Change } \\
\text { Percent }\end{array}$} \\
\hline & & $\begin{array}{c}\text { No. of } \\
\text { responses }\end{array}$ & Percent & $\begin{array}{c}\text { No. of } \\
\text { responses }\end{array}$ & Percent & \\
\hline Trip & Single day trip & 253 & 18.28 & 504 & 36.42 & 18.14 \\
\hline \multirow[t]{3}{*}{ Duration } & $1-3$ days & 779 & 56.29 & 634 & 45.81 & -10.48 \\
\hline & 4-6 days & 215 & 15.53 & 153 & 11.05 & -4.48 \\
\hline & Six days above & 156 & 11.27 & 124 & 8.96 & -2.31 \\
\hline \multirow[t]{7}{*}{ Travel date } & Monday & 118 & 8.53 & 95 & 6.86 & -1.67 \\
\hline & Tuesday & 80 & 5.78 & 61 & 4.41 & -1.37 \\
\hline & Wednesday & 54 & 3.90 & 57 & 4.12 & 0.22 \\
\hline & Thursday & 44 & 3.18 & 53 & 3.83 & 0.65 \\
\hline & Friday & 133 & 9.61 & 148 & 10.69 & 1.08 \\
\hline & Weekends & 372 & 26.88 & 304 & 21.97 & -4.91 \\
\hline & Any time & 797 & 57.59 & 908 & 65.61 & 8.02 \\
\hline \multirow[t]{5}{*}{ Departure time } & Early morning & 644 & 46.53 & 476 & 34.39 & -12.14 \\
\hline & Morning & 375 & 27.10 & 469 & 33.89 & 6.79 \\
\hline & Noon & 184 & 13.29 & 292 & 21.10 & 7.81 \\
\hline & Afternoon & 412 & 29.77 & 632 & 45.66 & 15.89 \\
\hline & Evening & 190 & 13.73 & 240 & 17.34 & 3.61 \\
\hline
\end{tabular}

Source: Authors' collection.

\subsubsection{Trip intensity and direction}

Trip intensity and direction were calculated to further understand travel behavior changes caused by HSR. Trip intensity measures the level of travel demand between a certain O-D pair, whereas trip direction captures the spatial orientation and distributional tendency of travel demand. Specifically, the absolute intensity can be illustrated as:

$$
\alpha_{A}=\frac{n_{i}}{S} \times 100
$$

where $\alpha_{A}$ denotes absolute intensity, $n_{i}$ refers to the number of inflow (or outflow) in region $i$, and $S$ refers to sample size. Conversly, the relative intensity measures the average trip per person, which is derived using the absolute intensity index divided by the population of the origin/destination. The relative intensity can be illustrated as:

$$
\alpha_{R}=\frac{n_{i}}{C_{i}} \times 10^{7}
$$

where $\alpha_{R}$ refers to relative intensity and $C_{i}$ represents the population in region $i$. 
As summarized in Table 6, it is not surprising that most HSR riders came from Chengdu and Chongqing, which account for $31.4 \%$ and $32.6 \%$ of the entire survey sample, respectively. In the Chongqing-bound survey, passengers were also from intermediate cities such as Neijiang, Luzhou, and Ziyang. The results also show that passengers came from other cities in the Sichuan province, such as Mianyang, Deyang, and Leshan. In the Chengdu-bound survey, many passengers were found to come from neighboring cities near Chongqing as well, such as Rongchang, Yongchuan, Bishan, and Wanzhou. Overall, the ranking of absolute intensity is generally consistent with that of relative intensity, which confirms that the survey provides a reasonable coverage of the population distribution in this region.

Table 6. Trip intensity ranked by the origin of the survey respondents

\begin{tabular}{|c|c|c|c|c|c|c|c|c|}
\hline \multirow[b]{2}{*}{ Ranking } & \multicolumn{4}{|c|}{ Desintation: The Chengdu East Station } & \multicolumn{4}{|c|}{ Destination: The Chongqing North Station } \\
\hline & Origin & $\begin{array}{l}\text { Absolute } \\
\text { Intensity }\end{array}$ & Origin & $\begin{array}{l}\text { Relative } \\
\text { Intensity }\end{array}$ & Origin & $\begin{array}{l}\text { Absolute } \\
\text { Intensity }\end{array}$ & Origin & $\begin{array}{l}\text { Relative } \\
\text { Intensity }\end{array}$ \\
\hline 1 & Chengdu & 31.43 & Chengdu & 273.28 & Chongqing & 32.59 & Chongqing & 529.47 \\
\hline 2 & Neijiang & 6.79 & Neijiang & 250.89 & Rongchang & 2.17 & Rongchang & 425.95 \\
\hline 3 & Luzhou & 1.52 & Ziyang & 70.85 & Yongchuan & 1.37 & Yongchuan & 172.73 \\
\hline 4 & Ziyang & 1.30 & Luzhou & 48.76 & Bishan & 0.79 & Bishan & 150.68 \\
\hline 5 & Mianyang & 0.87 & Deyang & 31.25 & Wanzhou & 0.58 & Dazu & 64.18 \\
\hline 6 & Deyang & 0.79 & Leshan & 27.57 & Dazu & 0.36 & Wulong & 57.80 \\
\hline 7 & Leshan & 0.65 & Meishan & 26.66 & Jiangjin & 0.29 & Wanzhou & 49.28 \\
\hline 8 & Meishan & 0.58 & Zigong & 25.17 & Fuling & 0.22 & Liangping & 45.18 \\
\hline 9 & Zigong & 0.51 & Mianyang & 24.94 & Liangping & 0.22 & Jiangjin & 29.56 \\
\hline 10 & Liangshan & 0.29 & $A^{\prime} b a$ & 21.40 & Qijiang & 0.14 & Tongnan & 29.31 \\
\hline 11 & Guang'an & 0.22 & Panzhihua & 16.19 & Tongnan & 0.14 & Fuling & 26.13 \\
\hline 12 & Dazhou & 0.14 & Ya'an & 12.99 & Wulong & 0.14 & Shizhu & 26.08 \\
\hline 13 & Nanchong & 0.14 & Guang'an & 9.19 & Fengdu & 0.07 & Qijiang & 24.68 \\
\hline 14 & Panzhihua & 0.14 & Liangshan & 8.29 & Nanchuan & 0.07 & Nanchuan & 17.46 \\
\hline 15 & Ya'an & 0.14 & Yibin & 4.43 & Yunyang & 0.07 & Fengdu & 16.13 \\
\hline 16 & Yibin & 0.14 & Guangyuan & 3.80 & Changshou & 0.07 & Zhongxian & 13.95 \\
\hline 17 & A'ba & 0.14 & Dazhou & 3.57 & Zhongxian & 0.07 & Changshou & 12.11 \\
\hline 18 & Guangyuan & 0.07 & Nanchong & 3.12 & Shizhu & 0.07 & Yunyang & 10.96 \\
\hline 19 & Suining & 0.07 & Suining & 3.03 & & & & \\
\hline
\end{tabular}

Note: The Chengdu East Station and the Chongqing North Station are considered as the destinations respectively in the calculation. Source: Authors' calculation.

Likewise, trip intensity was calculated by destinations in both directions. As illustrated in Table 7, approximately $35 \%$ of the passengers who departed from Chengdu rode HSR to Chongqing, and vice versa. When departing from Chengdu, the destinations of most passengers were Neijiang, Bishan, Ziyang, Wanzhou, and Yongchuan. Conversely, although the final destination of over one-third of the passengers was Chengdu, the rest of the passengers who departed from Chongqing traveled primarily to Rongchang, Yongchuan, Neijinag and Dazu. Again, the ranking of absolute intensity is consistent with that of relative intensity. Another interesting finding is that the top destination of passengers who departed from the Chongqing North Station was Rongchang after normalizing by population, which suggests that travel intensity is high from Chongqing to Rongchang if it is measured in terms of average trip per person. 
Table 7. Trip intensity ranked by the destination of the survey respondents

\begin{tabular}{|c|c|c|c|c|c|c|c|c|}
\hline \multirow[b]{2}{*}{ Ranking } & \multicolumn{4}{|c|}{ Departure from: The Chengdu East Station } & \multicolumn{4}{|c|}{ Departure from: The Chongqing North Station } \\
\hline & Destination & $\begin{array}{l}\text { Absolute } \\
\text { Intensity }\end{array}$ & Destination & $\begin{array}{l}\text { Relative } \\
\text { Intensity }\end{array}$ & Destination & $\begin{array}{l}\text { Absolute } \\
\text { Intensity }\end{array}$ & Destination & $\begin{array}{l}\text { Relative } \\
\text { Intensity }\end{array}$ \\
\hline 1 & Chongqing & 34.83 & Chongqing & 565.86 & Chengdu & 34.18 & Rongchang & 681.53 \\
\hline 2 & Neijiang & 11.34 & Bishan & 424.66 & Rongchang & 3.47 & Yongchuan & 354.55 \\
\hline 3 & Bishan & 2.24 & Neijiang & 419.05 & Yongchuan & 2.82 & Chengdu & 297.16 \\
\hline 4 & Ziyang & 2.02 & Yongchuan & 163.64 & Neijiang & 2.31 & Dazu & 141.21 \\
\hline 5 & Wanzhou & 1.52 & Wanzhou & 129.37 & Dazu & 0.79 & Neijiang & 85.41 \\
\hline 6 & Yongchuan & 1.30 & Ziyang & 110.21 & Mianyang & 0.14 & Shizhu & 25.87 \\
\hline 7 & Chengdu & 0.43 & Dazu & 77.02 & Leshan & 0.14 & Bishan & 13.70 \\
\hline 8 & Dazu & 0.43 & Dianjiang & 58.11 & Ziyang & 0.14 & Changshou & 12.11 \\
\hline 9 & Dianjiang & 0.29 & Rongchang & 56.79 & Deyang & 0.14 & Panzhihua & 8.09 \\
\hline 10 & Rongchang & 0.29 & Liangping & 45.18 & Changshou & 0.07 & Ziyang & 7.87 \\
\hline 11 & Liangping & 0.22 & Changshou & 24.22 & Bishan & 0.07 & Leshan & 6.13 \\
\hline 12 & Zigong & 0.14 & Fengjie & 13.51 & Shizhu & 0.07 & Deyang & 5.68 \\
\hline 13 & Changshou & 0.14 & Fuling & 8.71 & Panzhihua & 0.07 & Mianyang & 4.16 \\
\hline 14 & Mianyang & 0.07 & Zigong & 7.19 & Guangyuan & 0.07 & Guangyuan & 3.80 \\
\hline 15 & Luzhou & 0.07 & Chengdu & 3.77 & & & & \\
\hline 16 & Fengjie & 0.07 & Luzhou & 2.32 & & & & \\
\hline 17 & Fuling & 0.07 & Mianyang & 2.08 & & & & \\
\hline
\end{tabular}

Note: The Chengdu East Station and the Chongqing North Station are considered as the origins respectively in the calculation. Source: Authors' calculation.

\section{$5 \quad$ Empirical analysis}

The empirical analysis addresses the following key questions: First, how did the economic linkage between Chengdu and Chongqing change after the opening of HSR? Second, how did the migration pattern alter after the opening of HSR? Third, what socioeconomic factors affected the trip frequency change caused by HSR?

\subsection{Economic linkage}

Following Li et al. (2009) and Li et al. (2014), the spatial gravity index was adopted to measure the variation of the economic linkage between Chengdu and Chongqing. Specifically, the index is expressed as:

$$
R_{i j}=\left(\sqrt{P_{i} G_{i}} \times \sqrt{P_{j} G_{j}}\right) / D_{i j}^{2}
$$

where $R_{i j}$ refers to the index of the economic linkage between region $i$ and $j$, and $P_{i}$ and $P_{j}$ represent the population in region $i$ and $j$, respectively. $G_{i}$ and $G_{j}$ denote the GDP of the two cities, respectively. $D_{i j}$ represents the shortest travel time by HSR between the two cities.

Given that the Chengyu HSR began operation on December 26, 2015, 2015 is considered as the year before HSR, whereas 2016 is the year after the opening of this service. The calculation result shows that the index was 905.0 in 2015, and the value increased to 4254.4 in 2016 . The different results suggest that the economic linkage between the two cities increased by 3.7 times after HSR went into operation. 


\subsection{Migration}

Following Li et al. (2009), the index of migration was calculated to examine whether the migration pattern was altered after the introduction of Chengyu HSR. Specifically, the index of unidirectional migration can be illustrated as:

$$
P_{(i-j)}=\frac{\sum_{k=0}^{m} a_{(i-j, k)} \cdot f_{(k)}}{N_{i}},(i \neq j)
$$

where $P_{(i-j)}$ refers to the frequency of the average outflow from city $i$ to $j . a_{(i j ;, k)}$ represents the number of respondents with a travel frequency of $k(0 \leq k \leq m, m=0,1,2,3, \ldots) \cdot f_{k}$ denotes different levels of travel frequency, which in this case represents six categories: "never", "twice a year", "once every two months", "once a month", "once a week" and "twice a week". Hence, the value of each category is specified as: $f_{0}=0$, $f_{1}=2, f_{2}=6, f_{3}=12, f_{4}=48, f_{5}=96 . N_{i}$ represents the number of valid samples in each city. Hence, the index of migration of the two directions in the corridor can be represented as:

$$
P_{i j}=P_{i j}+P_{i j},(i \neq j)
$$

Table 8. Passenger flow analysis: Measured by the index of migration

\begin{tabular}{lrrr}
\hline Index & Before the Operation of the HSR & After the Operation of the HSR & Growth Rate \\
\hline Chongqing-Chengdu $P_{(i-j)}$ & 16.63 & 27.49 & 65.30 \\
Chengdu-Chongqing $P_{(j-i)}$ & 18.93 & 29.36 & 55.10 \\
Aggregate Index $P_{i j}$ & 35.56 & 56.85 & 59.87 \\
\hline
\end{tabular}

Source: Authors' calculation.

\subsection{Factors affecting the travel demand}

To investigate what factors affect the intercity travel demand changes between Chengdu and Chongqing, an econometric analysis was implemented based on the survey data. Specifically, an ordered probit model was adopted following Li et al. (2014). The model is specified as:

$$
Y_{i}=\beta X_{i}+\varepsilon_{i}
$$

where $Y_{i}$ denotes the dependent variable, which is measured by the variations of travel frequency before and after the opening of HSR. $X_{i}$ represents independent variables, $\beta$ represents the coefficients to be estimated, and $\varepsilon_{i}$ denotes the error term. The descriptions of the variables are summarized in Table $9 .{ }^{4}$

\footnotetext{
${ }^{4}$ The descriptive statistics and correlation matrix of the variables are illustrated in Appendix 2 and 3, respectively.
} 
Table 9. Description of the key variables

\begin{tabular}{|c|c|c|}
\hline Variable & Type & Categories \\
\hline $\begin{array}{l}\text { The change of travel frequency before and after } \\
\text { the opening of HSR }(\mathrm{Y})\end{array}$ & Ordered & $\begin{array}{l}\text { Increase in Annual Travel Frequency }=3 \\
\text { No Change in Annual Travel Frequency }=2 \\
\text { Decrease in Annual Travel Frequency }=1\end{array}$ \\
\hline Gender $\left(\mathrm{X}_{1}\right)$ & Unordered & Male $=1$, Female $=0$ \\
\hline Age $\left(\mathrm{X}_{2}\right)$ & Ordered & $\begin{array}{l}\text { Under } 18 \text { years old }=1 \\
18-25 \text { years old }=2 \\
25-40 \text { years old }=3 \\
40-60 \text { years old }=4 \\
\text { Over } 60 \text { years old }=5\end{array}$ \\
\hline Education level $\left(\mathrm{X}_{3}\right)$ & Ordered & $\begin{array}{l}\text { Professional school, or high school }=1 \\
\text { Junior college }=2 \\
\text { Undergraduate }=3 \\
\text { Master's or above }=4\end{array}$ \\
\hline Career $\left(\mathrm{X}_{4}\right)$ & Ordered & $\begin{array}{l}\text { Others }=0 \text {, Famer }=1 \text {, Student }=2, \\
\text { Worker }=3 \text {, Business man } / \text { woman }=4, \\
\text { Private owner }=5 \text {, Retiree }=6 \text {, Civil servant }=7\end{array}$ \\
\hline Monthly income $\left(\mathrm{X}_{5}\right)$ & Ordered & $\begin{array}{l}\text { Without any income }=1 \\
\text { Less than } ¥ 2,000=2 \\
¥ 2,001-5,000=3 \\
¥ 5,001-10,000=4 \\
\text { More than } ¥ 10,000=5\end{array}$ \\
\hline Trip purpose: business $\&$ commute $\left(\mathrm{X}_{6}\right)$ & Unordered & Yes $=1, \mathrm{No}=0$ \\
\hline Trip purpose: study $\left(\mathrm{X}_{7}\right)$ & Unordered & Yes $=1, \mathrm{No}=0$ \\
\hline Trip purpose: visit friends \& relatives $\left(\mathrm{X}_{8}\right)$ & Unordered & Yes $=1, \mathrm{No}=0$ \\
\hline Trip purpose: tour and shopping $\left(\mathrm{X}_{9}\right)$ & Unordered & Yes $=1, \mathrm{No}=0$ \\
\hline Trip purpose: returning home $\left(\mathrm{X}_{10}\right)$ & Unordered & Yes $=1, \mathrm{No}=0$ \\
\hline The reason for choosing HSR: time savings $\left(\mathrm{X}_{11}\right)$ & Unordered & Yes $=1, \mathrm{No}=0$ \\
\hline The reason for choosing HSR: fare $\left(\mathrm{X}_{12}\right)$ & Unordered & Yes $=1, \mathrm{No}=0$ \\
\hline The reason for choosing HSR: amenity $\left(\mathrm{X}_{13}\right)$ & Unordered & Yes $=1, \mathrm{No}=0$ \\
\hline The reason for choosing HSR: punctuality $\left(\mathrm{X}_{14}\right)$ & Unordered & Yes $=1, \mathrm{No}=0$ \\
\hline The reason for choosing HSR: safety $\left(\mathrm{X}_{15}\right)$ & Unordered & Yes $=1, \mathrm{No}=0$ \\
\hline
\end{tabular}

Source: Authors' calculation.

The regression analysis was conducted separately by the direction of demand. As illustrated in Table 10, Models 1 and 2 summarize the regression results based on the respondents who departed from Chengdu and Chongqing, respectively, whereas model 3 presents the aggregate results. It is clear that the factors which affect intercity travel demand are slightly different in the two models. For instance, the estimate of "tour and shopping" was found to be substantial and statistically significant in Model 1, whereas the estimate of "visiting friends and relatives" was found considerable and statistically significant in Model 2. Such findings suggest that the change of HSR travel demand is primarily attributed to the 
expansion of personal trips. More specifically, it appears that people are more likely to travel for tourism and shopping from Chengdu to Chongqing by HSR, whereas people are more likely to visit friends and relatives from Chongqing to Chengdu.

In addition, demographic variables such as age, education, and income were also found to have influences on travel demand change. For instance, negative estimates of the age variable were found among all three models, but only the estimate in Model 1 was found to be significant at the $10 \%$ level. This result indicates that the number of young travelers increases in HSR travel frequency, ceteris paribus. The estimates of gender were found negative and statistically significant in Model 2 and 3, which suggests that being a female is more likely to increase the travel frequency by HSR, ceteris paribus.

In terms of the motivation for choosing the Chengyu HSR, only the travel time-saving variable was found to be statistically significant, which suggests that people who appreciate travel time-saving tend to ride HSR more frequently.

Table 10. The results of the ordered probit regression analysis

\begin{tabular}{|c|c|c|c|c|c|c|}
\hline \multirow{3}{*}{ Variable } & \multicolumn{2}{|l|}{ Model 1} & \multicolumn{2}{|l|}{ Model 2} & \multirow{2}{*}{\multicolumn{2}{|c|}{$\begin{array}{l}\text { Model } 3 \\
\text { Combined }\end{array}$}} \\
\hline & \multicolumn{2}{|c|}{ Chengdu } & \multicolumn{2}{|c|}{$\begin{array}{l}\text { Departure from } \\
\text { Chongqing }\end{array}$} & & \\
\hline & & & & & Coef & Z-Sta. \\
\hline Gender $\left(\mathrm{X}_{1}\right)$ & -0.069 & -0.740 & $-0.296^{* * *}$ & -2.770 & $-0.158^{\star *}$ & -2.270 \\
\hline Age $\left(\mathrm{X}_{2}\right)$ & $-0.105^{\star}$ & -1.660 & -0.013 & -0.180 & -0.063 & -1.330 \\
\hline Education Level $\left(\mathrm{X}_{3}\right)$ & -0.027 & -0.520 & $0.127^{\star \star}$ & 2.190 & 0.038 & 1.000 \\
\hline Career $\left(\mathrm{X}_{4}\right)$ & 0.005 & 0.260 & -0.002 & -0.070 & 0.003 & 0.200 \\
\hline Monthly income $\left(\mathrm{X}_{5}\right)$ & 0.071 & 1.510 & 0.046 & 0.900 & $0.062^{*}$ & 1.790 \\
\hline Trip purpose: business \& commute $\left(\mathrm{X}_{6}\right)$ & 0.070 & 0.620 & 0.064 & 0.510 & 0.074 & 0.890 \\
\hline Trip purpose: study $\left(\mathrm{X}_{7}\right)$ & 0.000 & 0.000 & 0.244 & 1.430 & 0.118 & 1.040 \\
\hline Trip purpose: visiting friends \& relatives $\left(\mathrm{X}_{8}\right)$ & 0.136 & 1.380 & $0.301^{\star * \star}$ & 2.660 & $0.202^{\star * *}$ & 2.740 \\
\hline Trip purpose: tour and shopping $\left(\mathrm{X}_{9}\right)$ & $0.307^{* * *}$ & 2.880 & 0.085 & 0.740 & $0.210^{* * *}$ & 2.710 \\
\hline Trip purpose: returning home $\left(\mathrm{X}_{10}\right)$ & 0.038 & 0.400 & 0.141 & 1.200 & 0.079 & 1.080 \\
\hline The reason for choosing HSR: time savings $\left(\mathrm{X}_{11}\right)$ & 0.088 & 0.840 & $0.216^{*}$ & 1.800 & $0.140^{*}$ & 1.780 \\
\hline The reason for choosing HSR: fare $\left(\mathrm{X}_{12}\right)$ & -0.141 & -1.230 & -0.115 & -0.930 & -0.103 & -1.240 \\
\hline The reason for choosing HSR: amenity $\left(\mathrm{X}_{13}\right)$ & 0.116 & 1.250 & 0.114 & 1.060 & 0.114 & 1.640 \\
\hline The reason for choosing HSR: punctuality $\left(\mathrm{X}_{14}\right)$ & 0.153 & 1.570 & 0.041 & 0.380 & 0.092 & 1.290 \\
\hline The reason for choosing HSR: safety $\left(\mathrm{X}_{15}\right)$ & -0.085 & -0.800 & -0.087 & -0.700 & -0.091 & -1.130 \\
\hline Number of obs. & & 768 & & 616 & & 1,384 \\
\hline Log likelihood & & -593.788 & & -466.542 & & -1066.873 \\
\hline Prob. $>$ chi $^{2}$ & & 0.086 & & 0.006 & & 0.000 \\
\hline Pseudo $\mathrm{R}^{2}$ & & 0.019 & & 0.033 & & 0.019 \\
\hline
\end{tabular}

Note: ${ }^{* * *},{ }^{* *},{ }^{*}$ denote the estimate is statistically significant at the level of $1 \%, 5 \%$, and $10 \%$, respectively.

Source: Authors' calculation. 


\section{Conclusions}

HSR has experienced prosperous development in China over the past decade. Although previous studies have attempted to quantify the impact of HSR on travel demand, most analyses focus on HSR in developed regions, whereas little attention has been paid to the systems operating in less developed regions of China, such as the southwest. To fill the gap, this study evaluates the impact of HSR on intercity travel behavioral changes using the Chengyu PDL as an example. Based on a travel survey including 1,384 samples, this study shows that intercity travel demand between Chengdu and Chongqing increased substantially, by $60 \%$, after the operation of HSR. HSR has become the primary mode for intercity travel in this corridor. In addition, our study also found that the difference of demand in both directions was reduced after the operation of HSR. This suggests that HSR promotes a convergent growth of travel demand. Although most travelers ride HSR for personal trip purposes, our study found that business and commute trips were also on the rise. Overall, the study confirms that the economic linkage between Chengdu and Chongqing is enhanced due to the improved travel experience brought by HSR.

These research findings provide the following two implications for planning and policy decisionmaking. First, given that trip intensities were found to be strong in some intermediate cities such as Neijiang, Bishan, Yongchuan, Rongchang, and Wanzhou, local governments and planning agencies need to pay more attention to this trend in order to provide appropriate policies to tackle both the challenges and opportunities generated by HSR. For instance, since the intercity travel demand was found to have increased substantially after the operation of HSR, more efforts are needed to address the potential issues associated with demand change, such as urban sprawl, land use, and population management. Second, because travel time savings were found to be one of the key incentives for people to ride HSR, future transportation planning and policy should focus on promoting a modal integration in order to further reduce travel time costs. For instance, HSR could be connected more seamlessly with other modes of transportation (e.g., public transit) in order to improve the efficiency of door-to-door travel. This is particularly important given the fact that many HSR stations in China are built in suburban and rural areas where public transit is often poorly served (Chen \& Haynes, 2015b).

It should be noted that our study also has a few limitations, which could be improved through future research endeavors. For instance, one caveat is that the results could be potentially overestimated due to the fact that the D-train (which is known as a lower-level of high-speed train service) was not considered in the assessment. Given that the D-train was not operating in the new HSR route until very recently, it would be worthwhile re-conducting the survey so that the findings could be further validated. Another limitation is that the research was analyzed based on a single HSR route without considering the spillover effects of other HSR services. Given that other HSR lines, such as the Xi'an-Chengdu and Guizhou-Chongqing, also began their operations recently in this region, it would be interesting to expand the analysis so that the effects of other HSR services could be analyzed and compared.

\section{Acknowledgements}

The authors are grateful for the financial support received from the General Project Supported by the National Social Science Foundation of China (Grant No.16BJL121), and the Key Project of Humanities and Social Sciences Research Supported by Chongqing Municipal Education Commission (Grant No. 18SKGH047). We also appreciate the anonymous reviewers for providing invaluable comments on the earlier version of this paper. Additiontal thanks must be given for the help received from the School of Economics and Management of Chongqing Jiaotong University. The authors would also like to thank Luo Yuan, Peng Qin, Yang Doudou, Ma Kunyu, Xiong Xiaoyan, Liu Yinglin, Zhou Tianying, 
Bai Tianyu, Liu Xiaoguang, Chen Junhan, Li Zhaojing, Tang Ruoliang, Fan Rujia, Xiong Jianfei, and Mamatiimin Abdulkadir for providing excellent assistance on data collection. Finally, the authors want to thank Zhang Rui, Guan Haichang, Wang Yu, and He Jing for their help. 


\section{References}

Boarnet, M. G. (1996). The direct and indirect economic effects of transportation infrastructure. Retrieved from University of California Transportation Center working papers https://EconPapers.repec.org/ RePEc:cdl:uctcwp:qt1506r290.

Campos, J., \& de Rus, G. (2009). Some stylized facts about high-speed rail: A review of HSR experiences around the world. Transport Policy, 16(1), 19-28. doi: org/10.1016/j.tranpol.2009.02.008

Cascetta, E., Papola, A., Pagliara, F., \& Marzano, V. (2011). Analysis of mobility impacts of the high speed rome-naples rail link using withinday dynamic mode service choice models. Journal of Transport Geography, 19(4), 635-643. doi: dx.doi.org/doi:10.1016/j.jtrangeo.2010.07.001

Chan, C. S., \& Yuan, J. (2017). Changing travel behaviour of high-speed rail passengers in China. Asia Pacific Journal of Tourism Research, 22(12), 1221-1237. doi: org/10.1080/10941665.2017.1391303

Chen, C. L., \& Hall, P. (2011). The impacts of high-speed trains on British economic geography: A study of the UK's intercity 125/225 and its effects. Journal of Transport Geography, 19(4), 689-704. doi: org/10.1016/j.jtrangeo.2010.08.010

Chen, C. L., \& Hall, P. (2012). The wider spatial-economic impacts of high-speed trains: A comparative case study of Manchester and Lille sub-regions. Journal of Transport Geography, 24(4), 89-110. doi:org/10.1016/j.jtrangeo.2011.09.002

Chen, C. L. (2012). Reshaping Chinese space-economy through high-speed trains: Opportunities and challenges. Journal of Transport Geography, 22(2), 312-316. doi: org/10.1016/j.jtrangeo.2012.01.028

Chen, H., Sun, D., Zhu, Z., \& Zeng, J. (2016). The impact of high-speed rail on residents' travel behavior and household mobility: A case study of the Beijing-Shanghai Line, China. Sustainability, 8(11), 1187. doi: https://10.3390/su8111187

Chen, Z., \& Haynes, K. E. (2015a). Impact of high-speed rail on housing values: An observation from the Beijing-Shanghai line. Journal of Transport Geography, 43, 91-100. doi: org/10.1016/j. jtrangeo.2015.01.012

Chen, Z., \& Haynes, K. E. (2015b). Chinese Railways in the Era of High-speed. Bingley, UK: Emerald Group Publishing Limited. Retrieved from https://books.emeraldinsight.com/page/ $\operatorname{detail} /$ :k=9781784419851

Chen, Z., Xue, J., Rose, A. Z., \& Haynes, K. E. (2016). The impact of high-speed rail investment on economic and environmental change in China: A dynamic CGE analysis. Transportation Research Part A Policy \& Practice, 92, 232-245. doi: org/10.1016/j.tra.2016.08.006

Cheng, Y. S., Loo, B. P., \& Vickerman, R. (2015). High-speed rail networks, economic integration and regional specialization in China and Europe. Travel Behavior and Society, 2(1), 1-14. doi: org/10.1016/j.tbs.2014.07.002

Ding, J., Jin, F., Wang, J., \& Liu, D. (2013). Competition game of high-speed rail and civil aviation and its spatial effect-a case study of Beijing-Shanghai high-speed rail. Economic Geography, 33(5), 104-110. Retrieved from http://en.cnki.com.cn/Article_en/CJFDTotal-JJDL201305017.htm

Fang, D., \& Sun, M. (2014). Study on regional spatial structure reconfiguration in the era of high-speed rail. Contemporary Economic Management, 36(2), 63-66. Retrieved from http://en.cnki.com.cn/Article_en/CJFDTotal-DJGL201402013.htm

Garmendia, M., Ribalaygua, C., \& Ureña, J. M. (2012). High speed rail: Implication for cities. Cities, 29, S26-S31. doi: org/10.1016/j.cities.2012.06.005

Givoni, M., \& Dobruszkes, F. (2013). A review of ex-post evidence for mode substitution and induced demand following the introduction of high-speed rail. Transport Reviews, 33(6), 720-742. Retrieved from https://EconPapers.repec.org/RePEc:ulb:ulbeco:2013/152140

Gutiérrez, J., Gonzalez, R., \& Gomez, G. (1996). The European high-speed train network: Predicted 
effects on accessibility patterns. Journal of Transport Geography, 4(4), 227-238. doi: org/10.1016/ S0966-6923(96)00033-6

Gutiérrez, J. (2001). Location, economic potential and daily accessibility: An analysis of the accessibility impact of the high-speed line Madrid-Barcelona-French border. Journal of Transport Geography, 9(4), 229-242. doi: org/10.1016/S0966-6923(01)00017-5

Hall, P. (2009). Magic carpets and seamless webs: Opportunities and constraints for high-speed trains in Europe. Built Environment, 35(1), 59-69. Retrieved from http://www.jstor.org/stable/23289644

Haynes, K. E. (1997). Labor markets and regional transportation improvements: The case of high-speed trains, an introduction and review. The Annals of Regional Science, 31(1), 57-76. doi: org/10.1007/ s001680050039

Hou, X., Liu, S., Zhang, W., \& Hu, Z. (2011). Characteristics of commuting behaviors between Beijing and Tianjin influenced by high-speed trains. Economic Geography, 31(9), 1573-1579. Retrieved from http://en.cnki.com.cn/Article_en/CJFDTotal-JJDL201 109027.htm

Jiang, B., Chu, N., Xiu, C., Zhao, Y., Li, X., \& Luo, C. (2016). Comprehensive evaluation and comparative analysis of accessibility in the "four vertical and four horizontal" HSR networks in China. Acta Geographica Sinica, 71(4), 591-604. Retrieved from http://en.cnki.com.cn/Article_en/CJFDTotalDLXB201604006.htm

Jiao, J., Wang, J., Jin, F., \& Dunford, M. (2014). Impacts on accessibility of China’s present and future HSR network. Journal of Transport Geography, 40, 123-132. doi: org/10.1016/j.jtrangeo.2014.07.004

Jin, F., \& Wang, J. (2004). Railway network expansion and spatial accessibility analysis in China: 1906-2000. Acta Geographica Sinica, 59(2), 293-302. Retrieved from http://www.geog.com.cn/ $\mathrm{CN} / \mathrm{Y} 2004 / \mathrm{V} 59 / \mathrm{I} 2 / 293$

Kim, K. S. (2000). High-speed rail developments and spatial restructuring: A case study of the capital region in South Korea 1. Cities, 17(4), 251-262. doi: org/10.1016/S0264-2751(00)00021-4

Kivisto, P. (2012). Time-space compression. The Wiley-Blackwell Encyclopedia of Globalization. doi: org/10.1002/9780470670590.wbeog557

Li, J., Zhu, S., Li, A., Ma, H., \& Gu, Q. (2006). Trip characteristics of intercity and incity of Changzhutan urban agglomeration. Transportation Science \& Technology, 6, 69-72. Retrieved from http:// en.cnki.com.cn/Article_en/CJFDTotal-SKQB200606025.htm

Li, W., Jiang, J., \& Lou, Y. (2009). Research on the structural characteristics in mid-Zhejiang urban agglomeration based on the relationship analysis. Economic Geography, 29(10), 1644-1649. Retrieved from http://en.cnki.com.cn/Article_en/CJFDTotal-JJDL200910015.htm

$\mathrm{Li}, \mathrm{X}$., Liu, Y., \& Cao, L. (2014). Research about the influence of population space of flow under the high-speed railway construction. China Population Resources \& Environment, 24(6), 140-147. Retrieved from http://en.cnki.com.cn/Article_en/CJFDTotal-ZGRZ201406021.htm

Long, M., \& Meng, X. (2015). Urbanization, suburbanization and China's urban spatial expansion. Areal Research and Development, 34(3), 53-60. Retrieved from http://or.nsfc.gov.cn/handle/00001903-5/266822

Long, M., Meng, X., \& Li, G. (2019). Literature review of the overseas studies on the economic and spatial effect of high-speed rail. Urban Planning International, 34(01):99-107. URL http://kns.cnki. net $/ \mathrm{kcms} / \mathrm{detail} / 11.5583$.TU.20170823.0932.003.html

Lu, D. (2001). An analysis of spatial structure and optimal regional development. Acta Geographica Sinica, 2, 127-135. Retrieved from http://www.geogsci.com/EN/abstract/abstract21768.shtml

Ma, W., Wang, Y., \& Liu, S. (2012). Transportation infrastructure and population migration in China: An analysis based on gravity model. China Soft Science, 3, 69-78. Retrieved from http://en.cnki. com.cn/Article_en/CJFDTotal-ZGRK201203009.htm

Mou, Z., Li, M., \& Cui, D. (2014). Intercity travel behavior study under the integration of Guangzhou 
and Foshan. Urban Development Studies, 21(8), 44-49. Retrieved from http://en.cnki.com.cn/Article_en/CJFDTotal-CSFY201408008.htm

Perl, A. D., \& Goetz, A. R. (2015). Corridors, hybrids and networks: Three global development strategies for high-speed rail. Journal of Transport Geography, 42, 134-144. doi: org/10.1016/j.jtrangeo.2014.07.006

Rietveld, P. (1989). Infrastructure and regional development. Annals of Regional Science, 23(4), 255274. doi: org/10.1007/BF01579778

Shaw, S. L., Fang, Z., Lu, S., \& Tao, R. (2014). Impacts of high-speed rail on railroad network accessibility in China. Journal of Transport Geography, 40, 112-122. doi: org/10.1016/j.jtrangeo.2014.03.010

Wang, J., \& Jin, F. (2005). Railway network organization and spatial service system optimization in China. Acta Geographica Sinica, 60(3), 371-380. Retrieved from http://www.geog.com.cn/CN/ Y2005/V60/I3/371

Yu, S., Chen, G., Martínez, L. M., de Abreu e Silva, J. (2015). Bi-level cellular agent-based model: Simulation of potential impacts of high-speed rail on land cover change in the Lisbon Metropolitan Area, Portugal. Journal of Transport and Land Use, 8(3), 151-180. Retrieved from https://www.jtlu. org/index.php/jtlu/article/view/640/718

Zhong, Y., Huang, J., \& Wen, Y. (2015). Impact of high-speed railway on spatial pattern of Chinese cities' accessibility. Scientia Geographica Sinica, 35(4), 387-395. Retrieved from http://geoscien.neigae. ac.cn/CN/10.13249/j.cnki.sgs.2015.04.387

Zhou, J. (2015). Measure the urban adsorption capacity of China's high-speed rail. Chinese Journal of Social Sciences. Retrieved from http://www.cssn.cn/xk/xk_tp/201504/t201504131584169.shtml

\section{Appendices}

Appendices 1, $2 \& 3$ are available as a supplemental file at www.jtlu.org/index.php/jtlu/rt/suppFiles/1302/0. 